that, with the exception of those cases which show a positive therapeutic test, there is little concrete evidence to support it. In some of our cases Professor R. A. Morton kindly carried out estimations of the amount of carotene and vitamin $\mathbf{A}$ in the plasma, and in none was any significant decrease demonstrated. This agrees with the findings of Porter and Godding (1945) in relation to various skin disorders, and with those of Miller and others (1947) and Hyams and Bloom (1947) in respect of leucoplakia vulvae. The last-named workers were also unable to demonstrate any biochemical evidence of vitamin $C$ and vitamin $B_{2}$ deficiency. The negative findings in regard to vitamin $\mathbf{A}$, however, are not necessarily conclusive, because it is now known that the plasma content of this vitamin remains normal for very long periods after it has been completely withdrawn from the diet (Glover, Goodwin, and Morton, 1947) and is not easily altered by administering vitamin A. Moreover, local deficiency states, if present, cannot be demonstrated by examination of the blood and urine.

\section{Management and Treatment}

From the foregoing it is clear that the most important part of the management of pruritus vulvae is a thorough investigation to find the cause. This necessitates taking a very careful history and making a full physical examination, and the minimum requirements as regards special tests are: (a) repeated examination of fresh vaginal swabs for trichomonas and Oicium albicans and other fungi; $(b)$ fractional test meal; (c) full examination of the blood; $(d)$ glucose-tolerance test; and (e) biopsy of vulval skin in selected cases. Unless a cause can be found treatment is mostly unsatisfactory.

Antipruritic ointments are of little use except as temporary measures and perhaps to break the scratch habit. The injection of local analgesics gives disappointing results, and the division of all cutaneous nerves is usually shortlived in its effect. The place of radiotherapy in the treatment of pruritus vulvae is very strictly limited and should be used only as a last resort and after very careful consideration. Although it may give relief by a mechanism unknown, the pruritus, if caused by a persisting factor, usually returns. Moreover, $x$ rays and radium are apt to produce permanent skin damage, which can itself be the cause of intractable pruritus. Oestrogen therapy is useless except when there is clear evidence of failure of ovarian function, and it may even be dangerous in precancerous lesions such as leucoplakia.

Leucoplakia appears to be helped sometimes by emollients (including cod-liver oil) and also by the local application of heat as suggested by Savill (1940), the idea being to improve blood supply. Often, however, nothing short of vulvectomy is of real value, and this should not be deferred too long, because of the possibility of malignant disease. Excision is of limited value except for clearly demarcated lesions such as leucoplakia, and even then there is a tendency for the condition to recur in the surrounding areas. Unless there is evidence of achlorhydria, gross dietetic errors, or other lesions characteristic of a deficiency state, the empirical administration of vitamin preparations even in massive doses is rarely helpful, despite a few enthusiastic reports to the contrary. Moreover, if, as postulated above, any deficiency state in these cases is of local origin it is unreasonable to expect a response from such medication.

Throughout this paper the emphasis has been on the obscure and difficult cases of pruritus vulvae, and the same is true in regard to treatment. Lest it convey too gloomy a view of the general picture it is perhaps fitting to conclude by emphasizing that even in the present state of knowledge a definite organic cause amenable to treatment can be found in not fewer than four out of every five women who complain of pruritus vulvae, and in not more than $5 \%$ is it impossible to give real relief by one means or another.

\section{REFERENCES}

Berkeley, C., and Bonney, V. (1909). British Medical Journal, 2, 1739.

Frankland, A. W. (1948). Ibid., 1, 1023.

Ganado, W. (1945). Ibid., 1, 141.

Glover, J., Goodwin, T. W., and Morton, R. A. (1947). Biochem. J., 41, 97.

Goldsmith, W. N. (1939). Practitioner, 142, 36.

Haultain, W. F. T. (1948), Amer. J. Obstet. Gynec., 55, 698

Hughes, W. (1946). British Medical Journal, 2, 85

Hunt, Elizabeth (1943). Diseases Affecting the Vulva, 2nd ed. Kimpton, London.

Hyams, M. N., and Bloom, H. O. (1947). Amer. J. Obstet. Gynec., 53, 214.

Königstein, H. (1936). Wien. klin. Wschr., 49, 815.

MacCormac, H., Sandifer, P. H., and Jelliffe, A. M. (1946). British Medical Journal, 2, 48.

Miller, N. F., Parrott, M. H., Stryker, Joan, Riley, G. M., and Curtis, A.' C. (1947). Amer. J. Obstet. Gynec., 54, 543.

Porter, A., and Godding, E. W. (1945). British Medical Journal, 1, 840.

Rosenthal, S. R., and Sonnenschein, R. R. (1948). Amer. J. Physiol., 155, 186

Savill, Ànes (1940). Brit. J. Derm., 52, 321, 353.

Stannus, H. S. (1944). British Medical Journal, 2, 103, 140

Swift, B. H. (1932). Med. J. Aust., 2, 541.

(1936). J. Obstet. Gynaec. Brit. Emp., 43, 1053.

Walshe, F. M. R. (1942). Brain, 65, 106.

Whitfield, R. G. S. (1947). British Medical Journal, 2, 164.

Wright, E. J. (1944). Ibid., 2, 352.

\section{RELIEF OF POST-OPERATIVE PAIN AND ITS INFLUENCE ON VITAL CAPACITY}

BY

\author{
H. E. POOLER, M.B., D.A. \\ Senior Anaesthetist, Chesterfield Royal Hospital
}

It has been recognized for many years that post-operative pulmonary complications occur much more frequently after surgical operations involving the upper abdomen than after those on other parts of the body (King, 1933 ; Campbell and Gordon, 1942). It is indeed significant that we are now more likely to hear the expression "postoperative chest" than the more old-fashioned "postanaesthetic pneumonia."

In Table $I$ is shown the incidence of post-operative pulmonary complications in a series of 5,869 anaesthesias. These were all personally administered and examined postoperatively by me, thus introducing a reasonably constant factor and ensuring that approximately the same minimum of abnormal physical signs in a chest qualified it for the label "pulmonary complications."

TABLE I.-Post-operative Pulmonary Complications

\begin{tabular}{cc|c|c}
\hline Site of Operation & & No. of Cases & Pulmonary Complications \\
\hline $\begin{array}{ll}\text { Upper abdomen } \\
\text { Lower abdomen }\end{array}$ & $\cdots$ & 331 & $63(19 \%)$ \\
Outside abdomen & $\cdots$ & 1,334 & $145(10 \%)$ \\
\hline Total & $\cdots$ & 4,204 & $29(0.7 \%)$ \\
\hline
\end{tabular}

* Does not include thoracic surgery.

Why this high incidence of pulmonary complications following abdominal operations and especially those on the upper abdomen? Langton Hewer (1948) lists several main causes of post-operative lung complications, including "impaired respiratory movements after operation and 
reluctance of the patient to cough." It seems reasonable to conclude that the impaired movement and reluctance to cough are conditioned to a large extent by the pain elicited by these efforts.

Observation in the surgical wards will soon convince anyone that operations involving interference with the abdominal walls are much more productive of these conditions than are operations remote from the abdomen, and that the nearer the operation is to the diaphragm the more reluctant is the patient to cough and the greater is the impairment of respiratory movement, hence the greater likelihood of pulmonary complications.

Churchill and McNeil (1927) and later Powers (1928) showed that an upper abdominal operation lowered the vital capacity on the first post-operative day to $25-30 \%$ of the original volume, lower abdominal operations to $50 \%$ of the original volume, but operations on the limbs had little effect on vital capacity.

Table II shows some of the results obtained by me. They are quite typical of our usual findings. A portable spirometer (pneumometer) was used, and the patient was placed in approximately the same position in bed for all readings.

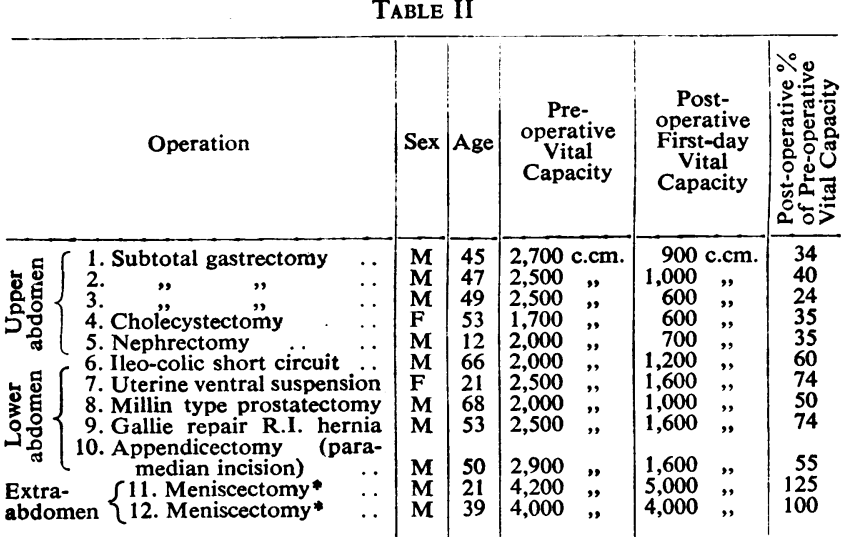

* It is interesting to note that the pre-operative vital capacity of Case 11 was measured half an hour after his premedication with " omnopon," gr. $\frac{1}{3}(22 \mathrm{mg}$.) and scopolamine. gr. $1 / 150(0.43 \mathrm{mg}$.), and that the post-operative readings of both Cases 11 and 12 were taken only ten hours after operation.

Lassen (1938-9) published similar figures. While he agrees that the fear of pain caused by coughing and deep breathing plays some part, he believes the chief factor is reflex muscle spasm, since the exhibition of morphine does not increase the post-operative vital capacity.

Morphine is still our great standby for the relief of pain, and in the absence of some strong contraindication no one would deny the drug to any patient after a severe operation. No doubt in vast numbers of cases it does a great deal of good and no harm. But morphine is well recognized as a respiratory depressant, so it cannot be an ideal drug to relieve pain when it is also desirable to increase pulmonary ventilation. With this latter factor in mind it was decided to try other methods of relieving post-operative pain, especially after upper abdominal operations. Apart from Lassen's work I have been unable to trace any literature dealing with the effect of sedative drugs on the post-operative vital capacity. In his article the only drug mentioned is morphine, and this very briefly. After some thought it was decided to use procaine in the form of an intravenous drip. Intravenous drip procaine had already become a recognized therapeutic measure (Lundy, 1942 ; Gordon, 1943 ; Graubard et al., 1947, 1948). It was felt that the dilute solutions required to produce general analgesia would not produce any significant decrease in muscle tone, especially in view of the wellknown fact that sensory anaesthesia is normally established before appreciable muscular paralysis occurs when dilute procaine solutions are used for nerve-blocking.

At first all that was sought was to produce a quick analgesia, then to encourage the patient to cough until sputum was produced, and then to carry out the routine breathing exercises as taught to him pre-operatively by the physiotherapist. This proved very satisfactory so far as it went. It was surprising, and most gratifying, to see the amount of sputum produced by a patient who had not previously complained of chest symptoms and had not experienced any desire to cough. It was felt that this routine of coughing followed by deep breathing must be preventing the onset of many potential areas of scattered atelectasis, and quite likely was clearing up some patches of collapse already established.

The technique used was a slow intravenous drip of $1 \%$ procaine in normal saline; the rate of the drip was carefully increased until the patient's pain was considerably relieved or until he complained of subjective symptoms such as "feeling light-headed" or "feeling dizzy." In practice these subjective symptoms always coincided with considerable relief of pain. In an average-sized adult this point was reached in about 5-10 minutes after the infusion of $15-20 \mathrm{ml}$. of the $1 \%$ solution. The drip was then slowed down and the coughing routine instituted. This technique necessitated the personal supervision of the anaesthetist, as it was obvious that the intravenous use of $1 \%$ procaine was not without its dangers and the well-known vagaries of intravenous drips precluded anything but continuous observation. In a hospital where anaesthetists are rather at a premium this technique could not be carried out on many patients.

The following three case reports are typical of the results obtained and indicate that the procedure is well worth while, despite the disappointing effect on the vital capacity after pain relief. As will be seen, the increase of vital capacity was not impressive.

\section{Case Reports : Technique I}

Case 1.-Man aged 45. Subtotal gastrectomy for chronic duodenal ulcer. Anaesthetic: soluble thiopentone, $1.7 \mathrm{~g}$., $\mathrm{N}_{2} \mathrm{O}+\mathrm{O}_{2}$, and $d$-tubocurarine, $25 \mathrm{mg}$. Duration: two hours and ten minutes. Pre-operative vital capacity: $2,700 \mathrm{c.cm}$. Post-operative vital capacity: first day, $900 \mathrm{c.cm}$. (34\% of pre-operative value). He already had a "rusty" sputum, and rales were heard in all areas. There was considerable pain, aggravated by coughing or attempted deep breathing. The intravenous drip transfusion of $1 \%$ procaine completely relieved his pain, enabled him to cough up a considerable amount of rusty mucopurulent sputum, and apparently enabled him to take deep breaths in comfort, but the vital capacity was increased by only $400 \mathrm{c.cm}$. to $1,300 \mathrm{c.cm}$. - that is, only $47 \%$ of its pre-operative value, a gain of $13 \%$ on the first postoperative reading.

Case 2.-Man aged 47. Subtotal gastrectomy for chronic duodenal ulcer. Anaesthetic: soluble thiopentone, $1.5 \mathrm{~g}$., $\mathrm{N}_{2} \mathrm{O}+\mathrm{O}_{2}$, and $d$-tubocurarine, $30 \mathrm{mg}$. Duration: two hours and five minutes. Pre-operative vital capacity: $2,500 \mathrm{c.cm}$. Postoperative vital capacity: first day, $1,000 \mathrm{c.cm}$. $(40 \%$ of preoperative value). Pain was fairly severe, and was much aggravated by attempted deep breathing. Intravenous transfusion of $1 \%$ procaine almost completely relieved his pain. Strong but painless coughing produced thick viscid sputum. Vital capacity increased by $200 \mathrm{c} . \mathrm{cm}$. to $1,200 \mathrm{c} . \mathrm{cm}$., or $48 \%$ of the pre-operative value-a gain of $8 \%$ on the first post-operative reading.

Case 3.-Man aged 49. Subtotal gastrectomy for chronic duodenal ulcer. Anaesthetic: soluble thiopentone, $1.75 \mathrm{~g}$., 
$\mathrm{N}_{2} \mathrm{O}+\mathrm{O}_{2}$ (minimal cyclopropane during closure of peritoneum), and $d$-tubocurarine, $35 \mathrm{mg}$. Duration: two and a half hours. Pre-operative vital capacity: 2,500 c.cm. Post-operative vital capacity: first day, $600 \mathrm{c.cm}$. (24\% of pre-operative value). Great deal of pain, much aggravated by attempted deep breathing. Intravenous transfusion of $1 \%$ procaine greatly relieved the pain. Vital capacity increased by $200 \mathrm{c.cm}$. to $800 \mathrm{c.cm}$., or $32 \%$ of pre-operative value-a gain of $8 \%$ on the first preoperative reading.

No serious subjective symptoms were encountered while using this technique. The initial drip is given very slowly, so that a patient with an idiosyncrasy to the drug would show mild warning symptoms before enough had been infused to do him real harm. Johnson and Gilbert (1946) have shown that reactions to procaine occurring during drip transfusions of the drug are easily controllable and need not be alarming. Using a $1 \%$ solution of procaine to obtain obstetric analgesia, they carry a patient into a semiconscious state for the actual delivery. Such dosages as " $8 \mathrm{~g}$. in 6 hours, $9.5 \mathrm{~g}$. in 8 hours, and $9.7 \mathrm{~g}$. in $8 \frac{1}{2}$ hours" illustrate the distance we have travelled since the time when intravenous injection of a local analgesic was looked upon as a serious accident occurring occasionally during the production of regional analgesia.

Since the publication of Barbour and Tovell's (1948) experiences using a $0.1 \%$ solution of procaine, with an average adult dosage of $1 \mathrm{~g}$. in one hour for the treatment of many different pathological conditions, I have used a similar technique for the relief of pain after upper abdominal operations. The advantages are that subjective symptoms of overdosage rarely occur and the patient need not be under personal supervision after the first few minutes. Actually, despite the greater dilution, the patient receives a much bigger dose, which appears to be a good deal more effective. The relief from pain is more lasting. With the use of Technique I ( $1 \%$ procaine) the patient obtains good relief for two to three hours. With Technique II $(0.1 \%$ procaine) the relief lasts as long as six to eight hours.

The solution used is procaine, $1 \mathrm{~g}$. in $1,000 \mathrm{ml}$. of $5 \%$ dextrose in normal saline. The procaine should not be mixed with the dextrose saline until required, as the resultant solution becomes discoloured after a few hours. The effect on the vital capacity is still disappointing, but is rather better than that achieved by Technique I, as the following typical case reports indicate.

\section{Case Reports : Technique II}

Case A.-Man aged 36. Subtotal gastrectomy for chronic duodenal ulcer. Anaesthetic: soluble thiopentone, $1.7 \mathrm{~g}$., $\mathrm{N}_{2} \mathrm{O}+\mathrm{O}_{2}$, and $d$-tubocurarine, $22.5 \mathrm{mg}$. Duration: two hours. Pre-operative vital capacity: $3,000 \mathrm{c.cm}$. Post-operative vital capacity: first day, $1,100 \mathrm{c.cm}$. (37\% of pre-operative value). Not severe pain-complete relief after $1 \mathrm{~g}$. of procaine, given in one hour by intravenous drip transfusion. Vital capacity increased by $500 \mathrm{c.cm}$. to $1,600 \mathrm{c.cm}$., or $53 \%$ of pre-operative value-a gain of $16 \%$. Post-operative vital capacity: second day, 1,800 c.cm. ( $60 \%$ of pre-operative value). After $1 \mathrm{~g}$. of procaine by intravenous drip, vital capacity increased to 2,100 c.cm., or $70 \%$ of pre-operative value-a further gain of $10 \%$.

Case B.-Man aged 46. Subtotal gastrectomy for recurrent gastric ulcer following partial gastrectomy three years previously. Anaesthetic: soluble thiopentone, $1.5 \mathrm{~g}$., $\mathrm{N}_{2} \mathrm{O}+\mathrm{O}_{2}$, and $d$-tubocurarine, $30 \mathrm{mg}$. (+minimal cyclopropane during maintenance to overcome hiccup). Duration: three hours. Preoperative vital capacity: $3,000 \mathrm{c.cm}$. Post-operative vital capacity: first day, $1,100 \mathrm{c.cm}$. ( $37 \%$ of pre-operative value) Not severe pain, but complete relief after $1 \mathrm{~g}$. of procaine in intravenous drip over one hour. Vital capacity increased by $400 \mathrm{c.cm}$. to $1,500 \mathrm{c.cm}$., or $50 \%$ of pre-operative value-a gain of $13 \%$. Post-operative vital capacity: second day, $1,500 \mathrm{c.cm}$. ( $50 \%$ of pre-operative value). After $1 \mathrm{~g}$. of procaine the vital capacity increased to $1,800 \mathrm{c.cm}$., or $60 \%$ of pre-operative value -a gain of $10 \%$.

Case C.-Man aged 52 ; a case of jejunal ulcer and gastrocolic fistula. Operation: undoing of 20-year-old gastrojejunostomy, closure of gastro-colic fistula, and subtotal gastrectomy. Anaesthetic: soluble thiopentone, 1.75 g., $\mathrm{N}_{2} \mathrm{O}+\mathrm{O}_{2}$, and $d$-tubocurarine, $30 \mathrm{mg}$., with occasional small doses of cyclopropane to secure quiet respiration during difficult surgical manipulation. Duration: three hours and ten minutes. Pre-operative vital capacity: 2,400 c.cm. Postoperative vital capacity: first day, $1,000 \mathrm{c.cm}$. (41\% of preoperative value). Rather severe pain much aggravated by attempted deep breathing. No desire to cough. Good relief obtained by procaine, $1 \mathrm{~g}$., in intravenous drip over one hour. No sputum produced by coughing. Deep breathing now almost painless. Vital capacity increased by $500 \mathrm{c.cm}$. to $1,500 \mathrm{c.cm}$., or $62 \%$ of pre-operative value-a gain of $21 \%$.

Case D.-Man aged 67. Repair of perforated duodenal ulcer. Anaesthetic: soluble thiopentone, $0.5 \mathrm{~g}$., $\mathrm{N}_{2} \mathrm{O}+\mathrm{O}_{2}$, and $d$-tubocurarine, $15 \mathrm{mg}$. Duration: 25 minutes. Pre-operative vital capacity: unknown. Post-operative vital capacity: first day, $1,000 \mathrm{c.cm}$. Severe pain. Great relief after $1 \mathrm{~g}$. in intravenous drip over one hour; coughing then produced copious sputum. Vital capacity increased to 1,200 c.cm. Post-operative vital capacity second day, $1,400 \mathrm{c.cm}$. No abnormal physical signs in the chest. There can be little doubt that this patient would have developed major pulmonary complications if he had not been able to expectorate freely on his first day.

For each case a vital capacity chart (a specimen of which is illustrated) is filled in, as well as the usual "CopelandChatterson" record card.

\section{Conclusion}

From the work done so far it would seem that Lassen (1938-9) is right when he asserts that the post-operative lowering of vital capacity is not altogether due to the fear of increase of pain on deep breathing. If this were the whole story, then complete relief of pain should restore the vital capacity to its normal volume, but this by no means happens. If, as seems likely, Lassen's assumption that reflex muscle spasm is the chief factor is correct, then something more than the abolition of conscious pain is required. In fact, it is likely that only by interrupting the reflex arc on its afferent side can we abolish this muscle spasm and still leave the muscles under full voluntary control, thus enabling the patient to take the deep breath required to produce his normal vital capacity.

Since writing the above I have had the opportunity of reading an article by $\mathrm{McCleery}$, Zollinger, and Lenahan (1948) in which they have shown that a significant increase of the post-operative vital capacity can be achieved, after upper abdominal operations, by injection of the sixth to the eleventh intercostal nerves with a slowly absorbed solution of $1: 1,000$ "nupercaine" in peanut oil. They claim that injection in the mid-axillary line does not interfere with the motor supply to the intercostal muscles. This procedure should not only relieve pain but should also break the reflex arc on the afferent side, yet the average increase of the vital capacity was still only 16 to $17 \%$, which is not much above the average increase obtained with intravenous procaine (12 to $13 \%$ ).

It seems not unreasonable to conclude that if we could hold a post-operative vital capacity at its pre-operative volume we should considerably reduce the incidence of post-operative pulmonary complications. But that this would not complete the story was shown by Rees-Jones (1941), who demonstrated that during the first 24 hours after an abdominal operation either the diaphragm on the 
ipsilateral side was fixed or its excursion very much reduced, while on the contralateral side movement was free; yet the only case in his series to develop pulmonary complications produced a lower-lobe atelectasis on the contralateral side.

\section{Summary}

The incidence of pulmonary complications following upper abdominal operations remains high.

After an upper abdominal operation the vital capacity is regularly decreased to the region of $35 \%$ of its pre-operative volume.

Intravenous drip procaine is an excellent method of relieving post-operative pain in cases in which it is important not to decrease pulmonary ventilation.

There is evidence that some increase of vital capacity follows the relief of post-operative pain by this method in abdominal cases. This increase, however, is so small that it is suggested that other theoretical causes for the lowered vital capacity need investigation.

\section{REFERENCES}

Barbour, C. M., and Tovell, R. M. (1948). Anesthesiology, 9, 514. Campbell, S. M., and Gordon, R. A. (1942). Canad. med. Ass. J. 46, 347 .

Churchill, E. D., and McNeil, D. (1927). Surg. Gynec. Obstet., 44 483.

Gordon, R. A (1943) Canad med Ass. J 49, 478.

Graubard; D. J., Robertazzi, R. W., and Peterson, M. C. (1947) N.Y.St. J. Med., 47, 2187 .

(1948). Curr. Res. Anesth., 27, 222

Hewer, C. Langton (1948). Recent Advances in Anaesthesia and Analgesia, 6th ed., p. 334 . London.

Johnson, K., and Gilbert, C. R. A. (1946). Curr. Res. Anesth., 26, 133

King, D. S. (1933). Surg. Gynec. Obstet., 56, 43

Lassen, H. K. (1938-9). Acta chir. scand., 81, 361

Lundy, J. S. (1942). Clinical Anesthesia, p. $392 . \quad$ Philadelphia.

McCleery, R. S., Zollinger, Robert, and Lenahan, Norris (1948). Surg. Gynec. Obstet., 86, 680.

Powers, J. H. (1928). Arch. Surg., 17, 304.

Rees-Jones, G. F. (1941). Brit. J.' Radiol., n.s. 14, 247.

\section{LOW-SALT DIET IN TREATMENT OF HYPERTENSION AND HYPERTENSIVE HEART DISEASE*}

\author{
H. O. BANG, M.D.
}

\section{P. BECHGAARD, M.D.}

AND

A. LEVIN NIELSEN, M.D.

(From Medical Departments 2 and 7 of the Municipal Hospital, Copenhagen)

The treatment of heart disease and hypertension has of late attracted much attention, thanks especially to papers by Allen and Sherrill (1922), Schroeder (1941), Schemm (1942), and White et al. (1946). Kempner (1944) claimed to have seen an exceptionally favourable response of hypertension to his salt-poor " rice diet." The favourable effect on these diseases was, however, observed far earlier by Karell (1866), Achard and Loeper (1901), and Widal and Lemierre (1903). In Denmark, Finsen (1904) proposed a low-salt diet in diseases associated with oedema. According to recent American experiences a rigorous restriction of the salt content of food (under 0.75 to $1 \mathrm{~g}$. of $\mathrm{NaCl}$ daily) is necessary, at least in the case of hypertension.

* Read before the Scandinavian Congress of Medicine, Copenhagen, on June 30

\section{Present Investigation}

Our object has been to test the above American results. In particular we have tried to prove that sodium chloride alone is the deciding agent and that the possible favourable response to the dietary treatment is not due to other factors, such as confinement to bed and rest in hospital.

Diet.-Originally we used a diet containing about 2,500 calories, but we soon had to reduce it to about 2,000 calories, the patients being unable to eat it all. The solid food consists of :

Morning: $45 \mathrm{~g}$. white bread (salt-free), $10 \mathrm{~g}$. butter (salt-free), 5 g. sugar, 1 g. tea.

Either simultaneously or later in the morning: $25 \mathrm{~g}$. oatmeal (as porridge, cooked without salt), $5 \mathrm{~g}$. sugar, $125 \mathrm{~g}$. stewed fruit.

Supper: $100 \mathrm{~g}$. white bread (salt-free), $30 \mathrm{~g}$. butter (salt-free), half an egg, $50 \mathrm{~g}$. tomato (or $100 \mathrm{~g}$. apple or $10 \mathrm{~g}$. cucumber), $25 \mathrm{~g}$. fresh meat (or $20 \mathrm{~g}$. fish), $10 \mathrm{~g}$. lemon juice with $10 \mathrm{~g}$. sugar (or $50 \mathrm{~g}$. juice in water).

Dinner consists of fruit jelly as the first dish (without milk), and boiled or fried (in salt-free butter) fish or meat, with vegetables and potatoes afterwards. The composition of the diet per day, calculated after Sherman's tables, appears to be : sodium $262 \mathrm{mg}$., chlorine $385 \mathrm{mg}$., calcium $254 \mathrm{mg}$., iron $7.9 \mathrm{mg}$., with protein $50 \mathrm{~g}$., fat $88 \mathrm{~g}$., and carbohydrate 258 g., giving 2,019 calories. The diet is insufficient with regard to calcium, and perhaps vitamin $B$ and iron. During the experimental periods we added daily doses of vitamins $\mathrm{A}$ and $\mathrm{D}$ and gave a weekly injection of a vitamin B preparation.

Material.-The series consisted of 26 patients, all admitted to the Municipal Hospital, Copenhagen. They presented 'such a degree of hypertension that after a fortnight's confinement to bed they still had a systolic blood pressure above $180 \mathrm{~mm}$. $\mathrm{Hg}$ and/or a diastolic pressure above $120 \mathrm{~mm}$. Hg. Seven of the patients were men and 19 women, with ages ranging between 45 and 71 years (average 59). Their hypertension had been recognized from well over 1 year up to 14 years previously. None of the patients seemed to suffer from the rapidly progressive malignant form of hypertension. The hypertension was in most cases complicated by heart disease (possibly with insufficiency), retinopathy, or nephropathy. In the accompanying table the patients have been grouped according to diagnosis, with the uncomplicated cases at the top, and then the different complications in order of increasing severity. Patients whose urea clearance was less than $50 \%$ of the normal value have been entered under a diagnosis of nephropathy. None of the patients had had syphilis or rheumatic fever.

Experimental Period.-During the preliminary fourteen days the blood pressure was measured frequently, and patients in whom it fell below the above limits were not submitted to treatment. A number of the less severe cases were therefore excluded. Four days before starting treatment with the low-salt diet we began to take the blood pressure of each patient in the morning; preferably this was done by the same physician, at least three times. The blood-pressure values are based on the lowest recorded for each day. The values stated in the table are means for the last four days. Column I gives means for the preliminary period, column II for the low-salt-diet period, and column III for the control period of high salt intake. During the preliminary period we measured the chloride and nitrogen excretion daily for two or three days. Ophthalmoscopy was carried out, as well as radiography of the heart, electrocardiography with precordial deflection, 